\title{
PENGARUH RETURN INDEKS NASDAQ, INDEKS S\&P DAN HARGA KUOTASI DOLAR TERHADAP TINGKAT RETURN SAHAM TELKOM
}

\author{
Arif Surahman \\ Dosen Prodi Manajemen Universitas Pamulang \\ dosen01176@unpam.ac.id
}

\begin{abstract}
ABSTRAK
Investasi pada instrumen saham memerlukan analisa yang akurat untuk terhindar dari kerugian. Asmara dan Suarjaya (2018) berhasil menemukan bahwa indikator-indikator makro berpengaruh signifikan terhadap fluktuasi harga IHSG. Pergerakan indeks harga saham sebuah negara terpengaruh oleh kondisi makro perekonomian dari negara tersebut (Deitiana, Stella, 2009). Kondisi perekonomian makro dari suatu negara saling pengaruh-mempengaruhi antara satu negara dengan negara lainnya, terutama apabila negara tersebut sudah sangat maju dan memiliki ekonomi yang kuat. Oleh karena itu, bisa diasumsikan bahwa Indeks Harga Saham Gabungan dari negara-negara yang sudah maju dapat turut mempengaruhi fluktuasi dari IHSG. Hal ini sebagaimana dibuktikan oleh hasil penelitian Tamara (2012) yang menemukan bahwa terdapat pengaruh yang signifikan antara Dow Jones Industrial Average, Shanghai Stock Exchange Composite Index dan Straits Times Index terhadap fluktuasi Indeks Harga Saham Gabungan. Penelitian sebelumnya yang dilakukan tahun 2019 oleh Deitiana dan Stella dengan menggunakan data harga penutupan mingguan dari Indeks Dow Jones, Nikkei 225, Kospi danShanghai Composite Index juga berhasil menemukan hubungan pengaruh yang signifikan baik secara simultan maupun parsial terhadap pergerakan IHSG.Penelitian ini menggunakan regresi linier sederhana untuk menyelidiki pengaruh indeks Nasdaq, S\&P dan harga dari quotasi dolar terhadap Return saham Telkom. Hasil dari penelitian ini menemukan bahwa Indeks Nasdaq dan harga quotasi Dolar terhadap Rupiah dapat mempengaruhi tingkat imbal hasil saham Telkom secara signifikan dengan nilai signifikansi berada dibawah 5\%.
\end{abstract}

Kata Kunci: Return, Saham, Telkom, Nasdaq, S\&P, Dolar.

\begin{abstract}
Investment in stocks recquire accurate analysis to avoid loss. Asmara and Suarjaya (2018) found that macro economic indicators of a country has a significant influence towards the fluctuations of IHSG prices. Deitana \& Stella (2019) also found the same thing. The Macro Economic conditions of a country has a reciprocal influnces between a country and others. Because of that, it can be assumed that stock indexes from an advanced country can also influenced the fluctuations of Indonesia's Stock Price Index. This assumption has been proven by the research which has been conducted by Tamara (2012) which found that there is a significant influence between Dow Jones Industrial Average, Shanghai Stock Exchange Composite Index and Straits Times Index towards the fluctuations of Indonesia Stock Price Index (IHSG). Previous research that were conducted in 2019 by Deitiana and Stella by using weekly closing price of Dow Jones Index, Nikkei 225, Kospi and Shanghai Composite Index also has found a significant connections either simultaneously nor partially to the movement of indonesia stock index prices. This research are conducted by using linier regression to investigate the influence of the return of Nasdaq, S\&P and Dollar to Rupiah quotations towards the Return of Telkom stock price. The results of this research concluded that Nasdaq Indices and Dolar price quotations towards Rupiah's can significantly influenced the return of telkom stock price with a confidence level that are below 5\%.
\end{abstract}

Keyword : Return, Stock, Telkom, Nasdaq, S\&P, Dolar. 


\section{PENDAHULUAN}

\section{Latar Belakang Masalah}

Melakukan investasi pada instrumen keuangan berupa saham dapat memberikan potensi keuntungan yang tak terhingga, tetapi juga dapat berpotensi untuk menimbulkan kerugian yang besar. Oleh karena itu, investor di pasar saham harus selalu mencari cara-cara supaya bisa selalu menghasilkan perdagangan saham yang menguntungkan.

Keuntungan yang didapatkan dari satu saham yang dimengerti dengan baik dapat mengalahkan keuntungan yang didapatkan apabila berinvestasi pada banyak saham dari perusahaan-perusahaan yang cara berbisnis dan prospek masa depannya tidak dimengerti dengan baik. Warren Buffet (2020) mengatakan bahwa "Anda harus berinvestasi pada perusahaanperusahaan yang cara berbisnisnya dimengerti dengan baik serta menawarkan prospek keuntungan jangka panjang". Oleh karena itu, penyelidikan tentang faktorfaktor yang bisa mempengaruhi tingkat imbal hasil dari suatu saham sangatlah penting untuk bisa diketahui. Investasi yang dilakukan tanpa pemahaman yang mendasar tentang bagaimana beroperasinya lingkungan internal dan eksternal bisnis perusahaan dapat mengakibatkan investor mengalami kebangkrutan.
Untuk mendapatkan pemahaman terhadap pergerakan sebuah saham, maka perlu dipahami terlebih dahulu hal apa yang mempengaruhi pergerakan Indek Saham pada suatu negara. Penelitian yang dilakukan oleh Asmara dan Suarjaya (2018) berhasil menemukan bahwa indikator-indikator makro berpengaruh signifikan terhadap fluktuasi harga IHSG. Pergerakan indeks harga saham sebuah negara terpengaruh oleh kondisi makro perekonomian dari negara tersebut (Deitiana, Stella, 2009). Kondisi perekonomian makro dari suatu negara saling pengaruh-mempengaruhi antara satu negara dengan negara lainnya, terutama apabila negara tersebut sudah sangat maju dan memiliki ekonomi yang kuat. Oleh karena itu, bisa diasumsikan bahwa Indeks Harga Saham Gabungan dari negaranegara yang sudah maju dapat turut mempengaruhi fluktuasi dari IHSG. Hal ini sebagaimana dibuktikan oleh hasil penelitian Tamara (2012) yang menemukan bahwa terdapat pengaruh yang signifikan antara Dow Jones Industrial Average, Shanghai Stock Exchange Composite Index dan Straits Times Index terhadap fluktuasi Indeks Harga Saham Gabungan. Penelitian sebelumnya yang dilakukan tahun 2019 oleh Deitiana dan Stella dengan menggunakan data harga penutupan mingguan dari Indeks Dow 
Jones, Nikkei 225, Kospi danShanghai Composite Index juga berhasil menemukan hubungan pengaruh yang signifikan baik secara simultan maupun parsial terhadap pergerakan IHSG.

Saham-saham perusahaan yang tercatat melakukan listing di bursa saham di Indonesia telah terbukti terpengaruh oleh pergerakan IHSG dan oleh karena itu berpotensi juga terpengaruh oleh pergerakan fluktuasi dari indeks-indeks saham yang terdapat di luar negeri. Penelitian yang dilakukan oleh Parulian, Subartini dan Riaman (2013) berhasil menemukan bahwa harga dari sahamsaham BCA, BRI, BNI, Bank Mandiri dan Bank Niaga terpengaruh secara signifikan oleh pergerakan fluktuasi IHSG. Lebih lanjut penelitian yang telah dilakukan oleh Sofian (2017) juga menemukan adanya pengaruh yang positif dan signifikan dari IHSG terhadap nilai aktiva bersih reksadana syariah di Indonesia yang merupakan kumpulan kombinasi sahamsaham campuran yang mengikutkan saham-saham yang terdapat didalam IHSG maupun diluar IHSG.

Kemudian Fadhilah (2018) berhasil menemukan bahwa DJIA, FTSE100, dan PSE berpengaruh positif dan signifikan terhadap JII (Jakarta Islamic Index), kemudian diikuti oleh NIKKEI 225 yang berpengaruh negatif dan signifikan terhadap JII (Jakarta Islamic Index). Hal ini membuktikan bahwa saham-saham individual juga bisa terpengaruh oleh bursa asing, terutama yang berasal dari negara maju. Oleh karena itu, penelitian saya akan mencoba menyelidiki bagaimana saham individu yang diproksi dengan saham PT. Telkom Tbk bisa memiliki kemungkinan dipengaruhi oleh pegerakan bursa saham asing yang berasal dari negara-negara maju.

Lebih lanjut, hubungan pengaruh yang signifikan antara harga Dolar Amerika terhadap Indeks Harga Saham Gabungan juga ditemukan pada penelitian terdahulu (Iraningsih, 2019). Dolar sebagai salah satu indikator makro ekonomi Indonesia diduga memiliki pengaruh terhadap pergerakan return saham individual, terutama terhadap return saham PT. Oleh karena itu, nilai kurs Dolar juga akan diselidiki pengaruhnya terhadap return saham individu.

Dalam penelitian ini digunakan data return perusahaan Telkom, dengan alasan bahwa saham PT. Telkom adalah saham yang masuk kedalam perhitungan indeks IHSG, LQ 45 dan JII dan terindeks pula oleh NYSE bursa saham Newyork. Selain itu, saham ini sangat stabil dan merupakan saham favorit bagi para investor ritel. Keistimewaan-keistimewaan tersebut menjadikan saham Telkom dapat 
dipilih untuk mewakili pergerakan saham individual.

Secara umum penelitian ini akan menyelidiki bagaimana perekonomian dari negara maju dan kuat bisa mempengaruhi perekonomian dari negara lain yang diukur dengan Indeks Harga Saham Gabungan Indonesia. Selain itu, novelty dalam penelitian ini adalah penggunaan Return Indeks Nasdaq dan Return S\&P 500 yang digunakan untuk mengkaji pengaruhnya terhadap Return saham Telkom. Oleh karena itu, judul dari penelitian ini adalah: Analisa Pengaruh Return Indeks Nasdaq, Return S\&P 500 dan harga kurs Dolar Terhadap Return Saham PT. Telkom.

\section{Idenfikasi Masalah}

Dari latar belakang penelitian yang telah dipaparkan di atas dapat disimpulkan beberapa masalah pada penelitian ini :

1. Apakah terdapat pengaruh dari return Indeks Nasdaq terhadap return saham Telkom?

2. Apakah terdapat pengaruh dari return S\&P500 terhadap return saham Telkom?

3. Apakah terdapat pengaruh harga kurs Dolar terhadap return saham Telkom?
4. Apakah terdapat pengaruh dari return Indeks Nasdaq, return S\&P500, dan harga kurs Dolar terhadap return saham Telkom?

\section{Perumusan Masalah}

Berdasarkan identifikasi masalah yang telah disebutkan diatas, maka dapat disimpulkan beberapa masalah yang terdapat pada penelitian ini, yaitu antara lain :

1. Bagaimanakah pengaruh dari return Indeks Nasdaq terhadap return saham Telkom?

2. Bagaimanakah pengaruh dari return S\&P500 terhadap return saham Telkom?

3. Bagaimanakah pengaruh harga kurs Dolar terhadap return saham Telkom?

4. Bagaimana pengaruh dari return Indeks Nasdaq, return S\&P500, dan harga kurs Dolar terhadap return saham Telkom?

\section{Tujuan Penelitian}

Tujuan yang ingin dicapai penulis pada penelitian ini adalah sebagai berikut :

1. Untuk mengetahui pengaruh dari return Indeks Nasdaq terhadap return saham Telkom. 
2. Untuk mengetahui pengaruh dari return S\&P500 terhadap return saham Telkom.

3. Untuk mengetahui pengaruh harga kurs Dolar terhadap return saham Telkom.

4. Untuk mengetahui pengaruh dari return Indeks Nasdaq, return S\&P500, dan harga kurs Dolar terhadap return saham Telkom.

\section{Metode Penelitian}

Penelitian ini memiliki sifat Deskriptif kuantitatif, yaitu penelitian yang menggunakan menggunakan pengolahan angka, setelah itu dilakukan deduksi yang berangkat dari teori-teori umum, kemudian ditariklah kesimpulan.

Alat analisa yang digunakan pada penelitian ini adalah regresi linier berganda.

\section{LANDASAN TEORI}

\section{Harga Saham}

Menurut Fahmi (2012), "pengertian saham adalah salah satu instrumen pasar modal yang paling banyak diminati investor karena mampu memberikan tingkat pengembalian yang menarik. Saham adalah kertas yang tercantum dengan jelas nominal, nama perusahaan, dan di ikuti dengan hak dan kewajiban yang telah dijelaskan kepada setiap pemegangnya".

\section{NASDAQ-100}

Menurut Wikipedia "NASDAQ100 adalah indeks pasar saham yang terdiri dari 100 perusahaan non-finansial terbesar yang terdaftar di NASDAQ. Indeks ini adalah indeks bobot kapitalisasi yang dimodifikasi. Bobot perusahaan dalam indeks ini didasarkan pada kapitalisasi pasarnya, dengan aturan-aturan tertentu yang menentukan pengaruh komponen terbesar. Indeks ini tidak memiliki perusahaan keuangan, dan meliputi beberapa perusahaan yang dibentuk di luar Amerika Serikat. Kedua faktor tersebut membedakannya dari Dow Jones Industrial Average, dan ketiadaan perusahaan keuangan membedakannya dari Indeks S\&P 500".

\section{S\&P 500}

Menurut Wikipedia, S\&P 500 adalah sebuah indeks yang terdiri dari saham 500 perusahaan dengan modal-besar, kebanyakan berasal dari Amerika Serikat. Indeks ini merupakan indeks paling terkenal yang dimiliki dan dirawat oleh Standard \& Poor's, sebuah divisi dari 
McGraw-Hill. Seluruh saham yang terdaftar dalam indeks ini adalah perusahaan publik besar dan diperdagangkan di bursa saham utama di AS seperti Bursa saham New York dan Nasdaq. Setelah Dow Jones Industrial Average, S\&P 500 adalah indeks yang paling banyak diperhatikan. Banyak dana indeks dan dana exchange-traded melacak performa S\&P 500 dengan memegang saham yang sama dengan indeks tersebut. Karena itu, sebuah perusahaan yang sahamnya dimasukkan ke dalam daftar ini, harga saham perusahaan tersebut akan meningkat.

Tabel 1: Perbedaan Komposisi S\&P 500 dengan Nasdaq 100

\begin{tabular}{|c|c|c|c|}
\hline \multicolumn{2}{|c|}{ S\&P $500-$ Top 5 sectors } & \multicolumn{2}{|c|}{ Nasdaq $100 \cdot$ Top 5 sectors } \\
\hline Sector & Weight & Sector & Woight \\
\hline Technology & $26 \%$ & Technology & $56 \%$ \\
\hline Health care & $15 \%$ & Consumer Goods \& Services & $29 \%$ \\
\hline Financials & $11 \%$ & Health Care & $8 \%$ \\
\hline Communication Services & $11 \%$ & Industrials & $5 \%$ \\
\hline Consumer Goods \& Services & $18 \%$ & Communication Services & $1 \%$ \\
\hline
\end{tabular}

\section{Sumber :https://blog.pluang.com/ cerdascuan/nasdaq-vs-sp-500/}

Sebagaimana terlihat pada tabel diatas, komposisi perhitungan indeks S\&P dan Nasdaq memiliki perbedaan yang besar, komposisi saham-saham teknologi yang dipakai pada perhitungan S\&P adalah sebesar $26 \%$, sedangkan pada perhitungan Nasdaq besarannya adalah 56\%. Pada bagian Consumer Goods \& Services Nasdaq menggunakan 29\% sedangkan S\&P 18\%. Pada bagian Health Care, Nasdaq menggunakan $8 \%$, sedangkan S\&P menggunakan bobot $15 \%$. Pada bagian Industrials, Nasdaq menggunakan 5\%, sedangkan S\&P menggunakan bobot $0 \%$. Pada bagian Financials, Nasdaq menggunakan $0 \%, \quad$ sedangkan $\mathrm{S} \& \mathrm{P}$ menggunakan bobot $11 \%$. Pada bagian Communication Services, Nasdaq menggunakan $1 \%, \quad$ sedangkan $\mathrm{S} \& \mathrm{P}$ menggunakan bobot $11 \%$.

\section{Operasionalisasi Variabel Penelitian}

Variabel penelitian adalah segala sesuatu yang akan menjadi objek pengamatan dari sebuah penelitian. Pada penelitian ini terdapat empat variabel, antara lain sebagai berikut :

\section{Return Saham Telkom (Y)}

Return saham Telkom adalah merupakan rasio perbandingan antara selisih harga saham harian ke-t dengan harga saham harian ke t-1 terhadap harga saham Telkom periode t-1 yang terdaftar listing di Bursa Efek Indonesia.

Return Indeks S\&P 500 (X1) 
Return Indeks S\&P 500 adalah merupakan rasio perbandingan antara selisih harga indeks ke-t dengan harga indeks ke $\mathrm{t}-1$ terhadap harga saham indeks periode $\mathrm{t}-1$ yang tercatat di Yahoo Finance.

\section{Return Indeks Nasdaq (X2)}

Return Indeks Nasdaq adalah merupakan rasio perbandingan antara selisih harga indeks ke-t dengan harga indeks ke t-1 terhadap harga saham indeks periode t-1 yang tercatat di Yahoo Finance.

\section{Harga Kurs Dolar (X3)}

Kurs harga dolar diambil dari website https://kursdollar.org/ dengan menggunakan harga jual.

\section{Kerangka Berfikir}

Merujuk dari tujuan yang ingin dicapai dalam penelitian ini, maka kerangka berfikir pada penelitian ini dapat digambarkan sebagai berikut:

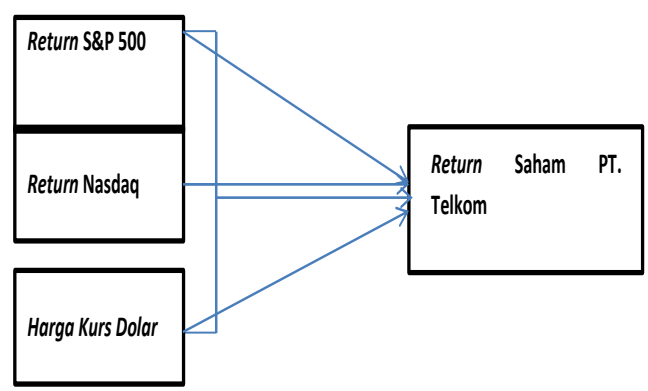

Gambar 1: Kerangka Berpikir

\section{Hipotesis Penelitian}

Hipotesis penelitian dibuat sebagai dugaan sementara sebelum penelitian yang sebenarnya dilakukan. Berdasarkan perumusahan masalah yang ditetapkan, maka dirumuskan hipotesis sebagai berikut:

Ho1 = Tidak terdapat pengaruh antara return S\&P 500 dengan return saham Telkom.

Ha1 = Terdapat pengaruh antara return S\&P 500 dengan return saham Telkom.

Ho2 = Tidak terdapat pengaruh antara return Nasdaq dengan return saham Telkom.

Ha2 = Terdapat pengaruh antara return Nasdaq dengan return saham Telkom.

Ho3 = Tidak terdapat pengaruh antara nilai harga kurs Dolar dengan return saham Telkom.

Ha3 = Terdapat pengaruh antara nilai harga kurs Dolar dengan return saham Telkom.

Ho4 = Tidak terdapat Pengaruh antara return S\&P 500, return Nasdaq dan harga kurs Dolar terhadap return saham Telkom.. Ha4 = Terdapat Pengaruh antara return S\&P 500, return Nasdaq dan harga kurs Dolar terhadap return saham Telkom.

\section{Analisis Deskriptif}

Analisis deskriptif mengemukakan tentang gambaran umum data, Hasil olahan 
data mengenai statistik deskriptif yang didapat dari SPSS adalah sebagai berikut:

Tabel 2: Statistik Deskriptif

\begin{tabular}{|l|r|r|r|}
\hline & \multicolumn{1}{|c|}{ Mean } & $\begin{array}{c}\text { Std. } \\
\text { Deviation }\end{array}$ & \multicolumn{1}{|c|}{$\mathrm{N}$} \\
\hline Rtelkom & $0,40 \%$ & $2,63 \%$ & 28 \\
RNdaq & $0,24 \%$ & $1,98 \%$ & 28 \\
RSnP & $0,29 \%$ & $1,20 \%$ & 28 \\
P Dol & 14746,946 & 252,3408 & 28 \\
\hline
\end{tabular}

Sumber : Output SPSS

Pada tabel diatas dapat diketahui bahwa Return harian saham Telkom memiliki rata-rata $0,39 \%$, selain itu, deviasinya adalah 2,63\%. Indeks Nasdaq dan S\&P memiliki rata-rata return harian sebesar $0,23 \%$ dan $0,28 \%$ disertai dengan Deviasi secara berurutan sebesar 1,98\% dan 1,20\%. Terakhir kurs Dolar terhadap Rupiah memiliki rata-rata harga quotasi harian sebesar Rp. 14746 disertai dengan deviasi sebesar Rp. 252,4.

\section{Koefisien Determinasi}

Nilai dari koefisien determinasi digunakan untuk mengetahui besarnya pengaruh fluktiasi variabel $\mathrm{X}$ terhadap variabel $\mathrm{Y}$, Berikut ini adalah nilai dari koefisien determinasi:

Tabel 3: Nilai Koefisien Determinasi

\begin{tabular}{|l|r|r|r|r|}
\hline Model & R & R Square & $\begin{array}{r}\text { Adjusted } \\
\text { R Square }\end{array}$ & $\begin{array}{c}\text { Std. Error } \\
\text { of the } \\
\text { Estimate }\end{array}$ \\
\hline 1 &, $640^{\mathrm{a}}$ & 0,41 & 0,336 & $2,14 \%$ \\
\hline
\end{tabular}
a. Predictors: (Constant), P Dol, RNdaq, RSnP
b. Dependent Variable: Rtelkom

Sumber : Output SPSS

Nilai Koefisien Determinasi yang sebagaimana terlihat pada tabel diatas mengandung informasi bahwa pergerakan fluktuasi harga Dolar, Return S\&P dan Nasdaq berpengaruh terhadap fluktuasi return saham Telkom sebesar $41 \%$.

\section{Uji Normalitas}

Untuk mendapatkan nilai Uji Normalitas, maka digunakanlah metode Uji Kolmogorov Smirnov. Berikut ini adalah tabel hasil pengujian yang didapatkan dari SPSS:

Tabel 4 : Hasil Uji Kolmogorov Smirnov

\begin{tabular}{|l|l|r|}
\hline \multicolumn{2}{|l|}{} & \multicolumn{1}{|c|}{$\begin{array}{c}\text { Unstandar } \\
\text { dized } \\
\text { Residual }\end{array}$} \\
\hline $\mathrm{N}$ & 28 \\
\hline Normal & Mean & 0 \\
Parameter & Std. & 2,017319 \\
$\mathrm{~s}^{\text {a,b }}$ & Deviation \\
Most & Absolute & 0,107 \\
Extreme & Positive & 0,107 \\
Difference & Negative & $-0,084$ \\
s & Nolmogorov-Smirnov & 0,566 \\
\hline Kon & & 0,906 \\
\hline Asymp. Sig. (2-tailed)
\end{tabular}

a. Test distribution is Normal.

b. Calculated from data.

Sumber : Output SPSS

Nilai Sig. (2-tailed) yang bernilai 0,906 menandakan bahwa tingkat signifikansi dari uji kolmogorov ini lebih 
besar daripada level kepercayaan $5 \%$. Alhasil dapat disimpulkan bahwa data yang digunakan pada penelitian ini terdistribusi secara normal.

\section{Uji Heteroskedastisitas}

Pengujian Heteroskedastisitas dilakukan dengan menggunakan uji glejser, yang hasilnya adalah sebagai berikut:

\section{Tabel 5 : Hasil Uji Glejser}

\begin{tabular}{|c|c|c|c|c|c|}
\hline \multirow[t]{2}{*}{ Model } & \multicolumn{2}{|c|}{$\begin{array}{c}\text { Unstandardized } \\
\text { Coefficients }\end{array}$} & \multirow{2}{*}{\begin{tabular}{|c|}
$\begin{array}{c}\text { Standardiz } \\
\text { ed } \\
\text { Coefficient } \\
\text { s }\end{array}$ \\
Beta \\
\end{tabular}} & \multirow[t]{2}{*}{$t$} & \multirow[t]{2}{*}{ Sig. } \\
\hline & B & Std. Error & & & \\
\hline (Constant) & 21,815 & 14,821 & & 1,472 & 0,154 \\
\hline 1 RNdaq & 0,153 & 0,143 & 0,236 & 1,069 & 0,296 \\
\hline $\mathrm{RSnP}$ & $-0,154$ & 0,237 & $-0,144$ & $-0,65$ & 0,522 \\
\hline P Dol & $-0,001$ & 0,001 & $-0,271$ & $-1,369$ & 0,184 \\
\hline
\end{tabular}

a. Dependent Variable: RES2

Sumber : Output SPSS

Nilai hasil uji-t terhadap data residual absolut dari model regresi mengatakan bahwa tidak ada variabel independen yang signifikan. Hasil ini mengatakan bahwa tidak terdapat heteroskedastisitas pada pemodelan regresi. Oleh karena itu, model regresi dapat digunakan.

\section{Uji Autokorelasi}

Uji autokorelasi dilakukan dengan menggunakan uji run. Berikut ini adalah hasil pengujiannya sebagaimana terdapat pada tabel dibawah ini :

\section{Tabel 6 : Hasil Uji Run}

\begin{tabular}{|l|r|}
\hline & $\begin{array}{r}\text { Unstandardized } \\
\text { Residual }\end{array}$ \\
\hline Test Vahe $^{\mathrm{a}}$ & $-0,26635$ \\
\hline Cases $<$ Test Vahe & 14 \\
\hline Cases $>=$ Test Vahe & 14 \\
\hline Total Cases & 28 \\
\hline Number of Runs & 13 \\
\hline Z & $-0,578$ \\
\hline Asymp. Sig. (2-tailed) & 0,563 \\
\hline a. Median & \\
\hline
\end{tabular}

Sumber : Output SPSS

Nilai dari Asymp. Sig (2-tailed) yang bernilai 0,563 berada diatas 0,05 . Kesimpulan yang dapat ditarik dari hal ini adalah tidak terdapat otokorelasi pada pemodelan regresi.

\section{Uji Multikolinieritas}

Untuk mendapatkan kesimpulan mengenai Multokolinieritas pada penelitan ini, maka dilihatlah nilai dari nilai Tolerance dan Variance inflation Factor (VIF). Berikut ini adalah tabel yang memuat kedua nilai tersebut: 
Tabel 7 : Hasil Uji Multikolinieritas

\begin{tabular}{|c|c|}
\hline \multicolumn{2}{|c|}{ Collinearity Statistics } \\
\hline Tolerance & VIF \\
\hline 0,772 & 1,295 \\
\hline 0,763 & 1,311 \\
\hline 0,96 & 1,042 \\
\hline
\end{tabular}

a. Dependent Variable: Rtelkom

Sumber : Output SPSS 26 (2020)

Berdasarkan hasil nilai diatas, diketahui bahwa semua nilai Tolerance berada pada angka yang lebih besar dari 0,10. Sementara itu nilai VIF semuanya lebih kecil dari 10 maka dapat disimpulkan bahwa tidak terjadi multikolinieritas pada pemodelan regresi.

\section{Uji F (Uji Simultan)}

Berikut ini adalah hasil pengolahan Uji $\mathrm{F}$ dengan menggunakan SPSS:

\section{Tabel 8 : Hasil Uji F}

\begin{tabular}{|ll|r|r|r|c|c|}
\hline \multicolumn{7}{|c|}{ Tabel : Uji F } \\
\hline & $\begin{array}{r}\text { Sum of } \\
\text { Squares }\end{array}$ & df & $\begin{array}{r}\text { Mean } \\
\text { Square }\end{array}$ & F & Sig. \\
\hline \multirow{4}{*}{ Sodel } & Regression & 76,328 & 3 & 25,443 & 5,557 &, $005^{\text {b }}$ \\
& Residual & 109,879 & 24 & 4,578 & & \\
\hline & Total & 186,207 & 27 & & & \\
\hline
\end{tabular}

a. Dependent Variable: Rtelkom

b. Predictors: (Constant), P Dol, RNdaq, RSnP

Nilai Sig. pada hasil uji $F$ yang terdapat pada tabel diatas mengatakan bahwa 0,005 berada diatas tingkat kepercayaan yang bernilai 0,05 . Hal ini menandakan bahwa secara simultan model ini signifikan mempengaruhi variabel $\mathrm{Y}$, atau dalam arti lain didalam model ini setidaknya terdapat satu variabel yang secara signifikan dapat mempengaruhi variabel Y.

\section{Uji t (Uji Parsial).}

Pengujian dengan menggunakan uji-t dilakukan untuk mengetahui signifikansi dari variabel-variabel independen parsial terhadap variabel dependennya.

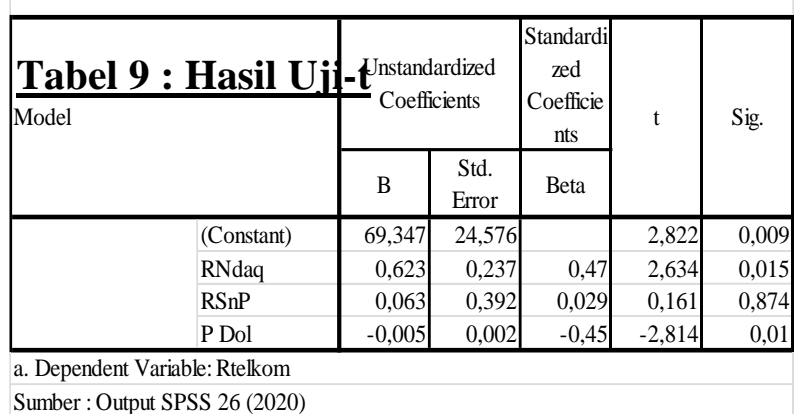

Dari hasil uji-t diatas dapat diketahui bahwa variabel yang secara signifikan mempengaruhi tingkat return saham PT. Telkom adalah variabel Return Nasdaq dan harga quotasi Dolar terhadap Rupiah yang memiliki tingkat signifikansi dibawah level kepercayaan, yaitu sebesar $0,015<0,05$ dan $0,01<0,05$.

\section{Kesimpulan}

Dari informasi yang terdapat pada tabel Uji-t diatas dapat disimpulkan bahwa variabel Return Nasdaq dapat secara signifikan mempengaruhi variabel return 
saham telkom dengan tingkat signifikansi sebesar 0,015 berada dibawah dari tingkat kepercayaan alpha 0,05. Slope dari variabel Return Nasdaq adalah sebesar $+0,623$.

Lebih lanjut, terkait dengan harga kuotasi kurs Dolar terhadap Rupiah dapat dikatakan bahwa variabel harga kurs Dolar terhadapa Rupiah dapat secara signifikan mempengaruhi variabel return saham telkom dengan tingkat signifikansi sebesar 0,01 berada dibawah dari tingkat kepercayaan alpha 0,05. Slope dari variabel Return Nasdaq adalah sebesar 0,005 .

Yang terakhir dari uraian diatas dapat diketahui bahwa variabel return S\&P

\section{DAFTAR PUSTAKA}

Parulian, S. \&. (2013). Analisis Pengaruh IHSG, Inflasi, BI Rate dan Nilai Tukar Rupiah terhadap Fluktuasi Harga Saham Bank Di Indonesia Menggunakan Metode Regresi Linear Berganda.

Rianingsih. (2019). ANALISIS PENGARUH HARGA KOMODITAS MINYAK DUNIA, HARGA EMAS, DAN NILAI TUKAR DOLLAR AMERIKA/RUPIAH TERHADAP INDEKS HARGA SAHAM GABUNGAN DI BURSA EFEK INDONESIA PERIODE 2012-2017.

SOFIAN, A. N. (2017). PENGARUH SERTIFIKAT BANK INDONESIA SYARIAH (SBIS), INFLASI DAN tidak dapat mempengaruhi tingkat return dari saham PT. Telkom.

Berdasarkan hasil uji $F$ dapat diketahui bahwa model regresi secara simultan mampu digunakan untuk memprediksi tingkat return dari saham Telkom.

\section{Saran}

Para investor sebaiknya memperhatikan fluktuasi dari return nasdaq dan fluktuasi dari harga quotasi Dolar terhadap Rupiah, terutama apabila ingin mempertimbangkan untuk melakukan investasi pada saham Telkom.

Stella, D. \&. (2009). PENGARUH INDEKS DOW JONES, NIKKEI 225,KOSPI, SHANGHAI COMPOSITE INDEX TERHADAP INDEKS HARGA SAHAM GABUNGAN BURSA EFEK INDONESIA PERIODE TAHUN 2004 -2008.

Suarjaya, A. d. (2018). PENGARUH VARIABEL MAKRO EKONOMI TERHADAP INDEKS HARGA SAHAM GABUNGAN.

Tamara. (2012). Pengaruh Dow Jones Industrial Average, Deutscher Aktien Index, Shanghai Stock Exchange Composite Index, dan Straits Times 
Index Terhadap Indeks Harga Saham

Gabungan di Bursa Efek Indonesia.

Rianingsih. (2019). ANALISIS PENGARUH

HARGA KOMODITAS MINYAK

DUNIA, HARGA EMAS, DAN

NILAI TUKAR DOLLAR

AMERIKA/RUPIAH TERHADAP

INDEKS HARGA SAHAM

GABUNGAN DI BURSA EFEK

INDONESIA PERIODE 2012-2017.

SOFIAN, A. N. (2017). PENGARUH

SERTIFIKAT BANK INDONESIA

SYARIAH (SBIS), INFLASI DAN

INDEKS HARGA SAHAM

GABUNGAN (IHSG) TERHADAP

NILAI AKTIVA BERSIH REKSA

DANA SYARIAH DI INDONESIA

(PERIODE 2012-2016).

Stella, D. \&. (2009). PENGARUH INDEKS

DOW JONES, NIKKEI 225,KOSPI,

SHANGHAI COMPOSITE INDEX

TERHADAP INDEKS HARGA

SAHAM GABUNGAN BURSA

EFEK INDONESIA PERIODE

TAHUN 2004 -2008.

Suarjaya, A. d. (2018). PENGARUH

VARIABEL MAKRO EKONOMI

TERHADAP INDEKS HARGA

SAHAM GABUNGAN.

Tamara. (2012). Pengaruh Dow Jones

Industrial Average, Deutscher Aktien

Index, Shanghai Stock Exchange

Composite Index, dan Straits Times

Index Terhadap Indeks Harga Saham

Gabungan di Bursa Efek Indonesia. 